\title{
Concept, Objectives and Challenges of Disaster Management
}

\author{
Amit Sinha ${ }^{1}$, Dr. Rajlaxmi Srivastava ${ }^{2}$ \\ ${ }^{1}$ Research Scholar, Institute of Management, Commerce and Economics, Shri Ramswaroop Memorial University, \\ Lucknow- Deva Road, UP. \\ ${ }^{2}$ Associate Professor, Institute of Management Commerce and Economics, Shri Ramswaroop Memorial University, \\ Lucknow- Deva Road, UP.
}

\begin{abstract}
Frequent calamities are causing huge losses and uncertainty to development. A well thought action plan for disaster management is the need of the hour and there should be sincere efforts to manage the problems of natural and man-made disaster. Against this background this paper is an attempt to discuss the meaning of disasters, their impact on human life and development, Sustainable Development and the idea of Disaster Risk Reduction and the objectives and challenges of disaster management. Nature has been an uncertain phenomenon causing huge human, environmental and economic losses by the events like earthquakes, floods, cyclone or even man-made calamities called disasters. Each disaster is capable of taking away the advancement made by mankind in a time frame of decades. So it important to understand issues related to disasters such as what is meant by the term disaster, factors responsible for them, the concept of disaster management, its objectives and challenges in national and international perspective, the development efforts integrating the concept of disaster risk reduction into development projects to have sustainable development. But India, with its geographical diversities, is a disaster prone nation. Its vast eastern coastline has been a regularly affected area from cyclone and tsunami. Himalayan belt is prone to landslide and cloud bursts, Uttarkashi and Kedarnath Valley tragedies cannot be ignored easily and so is the annual phenomenon of floods by the Ganga, Brahmpurta and allied rivers. Bhopal gas tragedy is still fresh in our minds. All these frequent calamities cause huge losses and uncertainty to development. A well thought action plan for disaster management is the need of the hour and there should be sincere efforts to manage the problems of natural and man-made disaster. Against this background this paper is an attempt to discuss the meaning of disasters, their impact on human life and development, Sustainable Development and the idea of Disaster Risk Reduction and the objectives and challenges of disaster management.
\end{abstract}

Keywords -Disaster Management concept, Objectives \& Principles, National \& International Approach.

\section{Introduction}

Disasters know no boundaries. Man-made or natural, technological or chemical it can strike at any moment anywhere, paving destruction in the present as well as in the future. There is no doubt that hazards are integral aspects of our environment. For centuries man considered disasters as the work of the evil spirits and tried to please them with magic and other rituals but later he started manipulating nature. Paradoxically this attempt to control nature has exposed the humanity to new threats. Disasters may be result of natural or human induced processes of events with the potential to create loss but exposure to a hazard need not necessarily mean disaster. It is the level of vulnerability of those exposed to the hazard that increases risk and the likelyhood of the disastrous occurrence [1]. As disasters are said to be boundary less the meaning attached to them also varies according to geo-sectors, geological and social settings in which they are located, and every new disaster adds dimension to human sufferings [2].

\section{Causes of Disaster}

There are many factors that can instigate the onset of a disaster. If we try to group them with a benchmark of frequency the responsible factors for disaster can be - a) Areas prone to Disaster, b) Location of residence, c) Density of population, d) Poverty, e) Global Warming, f) New Human Settlement Regions, g) technologies causing Disasters, h) Industrialization, i) Corruption etc. Areas prone to Disasters, due to tectonic plate movements and resultant seismic activities, volcanic eruptions, tsunami have increased and many parts of the world have been affected by tectonic disorder. For example, according to the Plate Tectonic Theory, the Indian peninsula which is a part of the Gondwana Landmass, keeps moving towards Tibetan region and because of this drift, the whole Himalayan region is prone to disasters like earthquakes and landslides and the plains below have witnessed frequent floods and drought. Location of residence is another important factor. The coastal areas are more vulnerable to cyclone than the interior region. Similarly a steep slope can be more prone to landslides. Density of population cannot be ignored as key factor inviting disasters. Densely populated areas are more prone to disaster. Since too many infrastructures like electric poles, telephone poles, cable lines, old buildings or poorly build structures are most of the time disaster prone. Poverty is another factor responsible for causing and enhancing the damage in disasters. Poor people are more vulnerable to disaster. It is because their disaster response is impeded by lack of resources [3]. Global Warming and related climatic changes due to both natural and anthropogenic factors can also be considered as another factor responsible for disaster. Numbers and severity of tropical cyclones have increased in the tropics. New human settlement regions, ever increasing human population and consequential increase in human settlements in more and more vulnerable and hazard prone area has led to increase in hazard risks and vulnerability mainly in poor and developing countries and India is one of them. Advanced Modern Technologies are causing never before technological disasters of various sorts and hence technological disasters are growing in numbers very fast [4]. Due to advent of new technologies pushing economic developments have invited new avenues of technological 


\section{International Journal of Science and Research (IJSR) \\ ISSN (Online): 2319-7064}

Index Copernicus Value (2015): 78.96 | Impact Factor (2015): 6.391

disasters. Industrialization has brought out developments on the one side and catastrophes on the other side as evident from the tragedies happened in at Union Carbide Plant in Bhopal and Chernobyl Plant in Russia. These two incidents causing death and serious injuries to thousands of innocent and helpless people had generated wide spread public concern and need for a comprehensive disaster management plan. Corruption is another dimension that can cause disaster. Often the authorities, who are assigned the task of proper management of the situation, show a tendency to meddle with the money and as a result the needy do not get the benefit to the fullest extent. The bureaucrats and high level politicians eat out the funds and the general public is devoid of the opportunity to tackle the situation [5].

\section{Hazard and Disaster: Meaning and Concept}

The term "Disaster" has been defined in many ways by scholars of various disciplines and the development and humanitarian communities. To understand full and complete meaning to the term 'disaster' certain allied words have to be considered, such as extreme events, hazards, vulnerability, disasters and environmental stress. Hazard is a dangerous phenomenon, substance, human activity or condition that may cause loss of life, injury or other health impacts, property damage, loss of livelihoods and services, social and economic disruption, or environmental damage [6]. The Term 'Vulnerability' means the extent to which a community, structure, service or geographic area is likely to be damaged or disrupted by the impact of particular hazard on account of its nature, constitution and proximity to hazardous terrain or a disaster prone area [7]. Vulnerability is the characteristics and circumstances of a community, system or asset that make it susceptible to the damaging effects of a hazard [8]. The word 'disaster' is derived from the 16th century word 'desastre'. The word is the combination of two Latin words - 'Dis' and 'Astro' means bad star. Therefore, disaster can be simply referred to as the unforeseen calamities caused by planetary. Disasters, whether natural or anthropogenic, are sudden adverse unfortunate extreme events or hazards which cause great damage to human beings as well as plants and animals. Disasters occur rapidly, instantaneously and indiscriminately. ... All the extreme events are hazards but not all the hazards are disasters. A hazard may become disaster only when it strikes the inhabited area. Etymologically three meanings are attributed to the term disaster, viz. (i) a state of extreme and usually irremediable ruin. The term is used in this sense when there is a great and sudden calamity; (ii) an event that brings terrible loss resulting in lasting distress, severe afflictions and injury to life; and (iii) an act that has disastrous consequences. The term is used in that sense when there is a total destruction and devastation [9]. From an economic perspective, however, a natural disaster can be defined as a natural event that causes a perturbation to the functioning of the economic system, with a significant negative impact on assets, production factors, output, employment, or consumption [10]. The Tampere Convention [11] defines 'disaster' as 'a serious disruption of the functioning society, posing a significant, widespread threat to human life, health, property or the environment, whether caused by accident, nature or human activity, and whether developing suddenly or as the result of complex long term processes. The ASEAN Agreement on Disaster Management and Emergency Response [12] determined that 'disaster' means a serious disruption of the functioning of a community or a society causing widespread human, material, economic, or environmental losses. When the cumulative effects of environmental hazards, environmental disasters and other forms of environmental degradation and pollution becomes so immense that the tolerance limit of the natural environment to assimilate them is surpassed and the environmental balance is disturbed, the resultant state of the highly disturbed natural environment is called environmental stress. It is evident that the environmental stress represents extreme limit of environmental degradation where the homeostatic mechanism of the natural system become unable to assimilate the adverse effects of hazards, disasters, environmental degradation and pollution [13].

\section{Conceptual Perspective of Disaster Management}

The approach towards disaster has been post disaster management, i.e. after the initial trauma on occurrence of disaster is over, within days, phase of reconstruction and rehabilitation will be over. ... But the increasing awareness about consequences of disasters brought the question of disaster management into forefront. Traditionally the response to disaster has been reactive with disbursement of fund for relief. There was no awareness of pre-disaster preparedness and mitigation activities earlier; soon there was a realization that there is a greater need for disaster mitigation activities, which can reduce the devastating effect of disaster. It is a fact that rehabilitation and reconstruction after disaster are costly. Thus there is a paradigm shift in thinking about disaster management from reduction to preaction. Disaster Management includes the range of activities designed to maintain control over disaster and emergency situation and to provide a framework for helping persons at risk to avoid or recover from the impact of disaster [14].

Disaster management is a complex multidisciplinary approach to tackle the pre and after effects of a disaster which occurs in a particular area or a region. Disaster Management is a process of comprehensive planning of an organization or a country or a province to protect the life and property of humans from expected or anticipated hazards and disasters and to provide immediate rescue and relief facilities to affected people by a disaster and also to facilitate recovery and rehabilitation programs [15]. Disaster management includes the development of disaster recovery plans (for minimizing the risk of disasters and for handling them when they do occur) and the implementation of such plans. Disaster/emergency management is the discipline of dealing with and avoiding risks. It involves preparing for a disaster before it happens, disaster response (e.g. emergency evacuation, quarantine, mass decontamination, etc.), as well as supporting and rebuilding society after natural or humanmade disasters have occurred. There are some other terms used for disaster management. Such as - Emergency Management, which has replaced Civil defense, can be seen as a more general intent to protect the civilian population in times of peace as well as in times of war. Civil Protection is

\section{Volume 6 Issue 7, July 2017}




\section{International Journal of Science and Research (IJSR) \\ ISSN (Online): 2319-7064}

Index Copernicus Value (2015): 78.96 | Impact Factor (2015): 6.391

widely used within the European Union and refers to government approved systems and resources whose task is to protect the civilian population, primarily in the event of natural and human-made disasters. Crisis Management is the term widely used in EU countries and it emphasizes the political and security dimension rather than measures to satisfy the immediate needs of the civilian population. Disaster risk reduction is an academic term which is growing, particularly for emergency management in a development management context. This focuses on the mitigation and preparedness aspects of the emergency cycle [16]. Disaster Management has evolved into a methodical technique. Basic aspect in disaster management is setting priorities and addressing some problems decisively in reference to other problems [17]. The fundamental aspects of disaster management program [18] include - i) disaster prevention [19], ii) disaster preparedness [20], iii) disaster response [21], iv) disaster mitigation [22], v) rehabilitation [23] and vi) reconstruction [24].

\section{Objectives of Disaster Management}

The world over disaster management is seen as evolving process. There cannot be a single model or approach towards management of disasters. Thus the objective of disaster management comprises six elements: the pre-disaster phase includes prevention, mitigation and preparedness, while the post disaster phase includes response, rehabilitation, reconstruction and recovery [25]. There is a saying that the more you sweat in peace the less you bleed in war is also applicable to the management of the disaster as well. Prevention is better than cure is more applicable here. Prevention is an area wherein government has a vital role to play. Having a techno legal regime that is enforced strictly is a precondition and falls exclusively in the domain of either the government or local bodies. The prevention planning, an integral part of everything we do, is aim for which all the agencies like government, industry, elected bodies, NGOs and community based organizations must strive. Attempts are being made by way of people's committees to manage natural resources in more and more eco-friendly manner. More thrust is needed on prevention mechanism. Mitigation in reference of disaster management is a key factor that can be deployed to minimize the destructive effects of hazards and thus lessen the scale of a possible disaster. This again is a matter that has to be linked to entire planning and implementation disaster management process. Capacity building of all the institution is also a pre-requisite and not only this they must be trained to handle post disaster scenarios. Preparedness in the disaster management can be seen as the maintenance of inventories of resources and the training of personnel to manage disasters are vital components of managing a disaster. Furthermore, this should be an ongoing, regular function of all departments, at all levels in active collaboration of people. These measures can be described as logistical readiness to deal with the disasters and can be enhanced by having response mechanisms and procedures, rehearsals, developing long term and short term strategies, public education and building early warning systems. Preparedness is the core area after the plans have been taken care of. There has to be standard operating procedure (SOPs) for every likely scenario. Generally response to disasters is emotive, people came out in large numbers to help their fellow citizens but it would be much better if they were professionally trained to manage such situations. Apart from police, home guards, NCC, scouts and guides volunteers from each locality must be trained and educated about the rescue and relief operations. Delayed Response in the event of disaster increases the vulnerability. Delays occur if the agencies responsible for handling the disaster situations have no clear plans. Search and rescue plans need to be clear and all role players need to know their role and function. Basic needs such as shelter, water food and medical care also have to be provided and a plan needs to be in place. Many times our response is adhoc and casual. Response including rescue and evacuation in a non-formal situation is specialized matter and nothing should be left to chance. Relief and Rehabilitation interventions are also required after a disaster occurs. In many ways this is the most difficult period for the victims. Immediate rescue and relief should be in a systematic way leading to job producing activities; construction works programs may be needed. The victims cannot be forgotten once the immediate disaster has passed. The economy must be brought back on the track. Every disaster tells us that there is no shortage of relief material but the distribution is mismanaged. Thus Professional Approach is required. Disaster Management requires genuine effort and commitment by all the stakeholders. The capacity must be built to handle such events and training programs are essential. Duplication of efforts should be minimized and financial resources must be appropriately controlled. Government cannot rely on normal procedures to implement appropriate responses - they need to learn special skills, techniques and attitudes in dealing with disasters. Disaster Management as a professional team based effort must be coordinated up to the village level in rural areas and ward level in urban areas where a team of volunteers must be in readiness to tackle the immediate impact of the disasters and at the same time there should be standing instructions to all the administrators in adjoining Districts and States to rush to the disaster site with all resources without any formal orders [26].

\section{Principles of Disaster Management}

Disaster management is a complex multidisciplinary approach to tackle to pre and post disaster effects in a particular area or region. The Federal Emergency Management Agency (FEMA) [27] has formulated the following principles for disaster management plans - a) It should be comprehensive, b) It should be progressive, c) It should be Risk Driven, d) It should be integrated, e) It should be Collaborative, f) It should be Coordinated, g) It should be flexible, h) It should be Professional. Emergency managers must consider all the aspects of hazards, i.e. hazard vulnerability and hazard risks, all phases of disaster management, i.e. pre and post disaster stages, all stakeholders and all aspects of disaster impact. They should identify hazard vulnerable areas and should anticipate impending disasters and to take necessary steps in advance for preventive and preparatory measures so that the communities may become able to develop disaster resilience. They should apply sound principles of risk management which include hazard identification, risk analysis and impact analysis. All efforts being made at all

\section{Volume 6 Issue 7, July 2017 www.ijsr.net}




\section{International Journal of Science and Research (IJSR) \\ ISSN (Online): 2319-7064}

Index Copernicus Value (2015): 78.96 | Impact Factor (2015): 6.391

management levels and all levels of government and all components of society and community should be integrated. There should be well integrated efforts to ensure coordination and relationships among individuals and organisations so that there becomes team spirit and consensus among all units. They should also facilitate communication at all levels. All activities related to disaster management should be coordinated and synchronized at all levels with all stakeholders, so that common purpose of management is well achieved. Disaster management programs should adopt such management approaches which are based on scientific knowledge, disaster education, training and experience. It should also be based on ethical value. There should be wide scope for further improvement in management mechanism. Disaster management plans should involve all resources which are available for daily purposes. Organisations involved in disaster management should function as an extension of their core business. Individual must be responsible for their safety. They should follow building code while constructing one's own house. Disaster management planning should focus on large-scale events such as earthquakes, tsunamis, hurricanes etc. which affect larger area and communities. Besides government Disaster Management should also involve NGOs. Disaster management planning must include the considerations of past history of extreme events in the area/ region considered and recurrence intervals of such events. Disasters Management Planning must be inter organizational and there should be enough communications exchange among various organisations. Make disaster mitigation and preparedness plans which may be adapted to wide range of circumstances. [28]

\section{Key Components of Disaster Management}

In order to have a successful disaster management program in place, we need to look at the main elements or key components of a Disaster Management plan. The processes and mechanism of disaster reduction and management include the following aspects - a) Hazard Analysis, b) Hazard vulnerability analysis and c) Hazard risk analysis. Hazards are those events which have potential to cause the loss of human life and property, social and economic disruption and environmental degradation. Hazard analysis process can be bifurcated in steps like - Framing of objectives of hazard analysis, hazard identification, hazard classification, factors of hazard information, causes of hazard occurrence and hazard profiles. Hazard Vulnerability Analysis is very important factor of disaster management as it helps in studying the cause and effect of various vulnerabilities. Hazard Risk Analysis for disaster management includes the consideration of the definition, components, assessment \& parameters of magnitude of hazard risks and hazard risk communication. Since hazard or disaster risk is a probability of likely adverse impacts of a particular hazard on society, it is full of uncertainties in terms of magnitude and severity of a hazard, speed, quantum of likely damage, duration of persistence of disaster etc. Similarly consequences of an event may be expressed in the terms of - a) human causalities or death, injuries to human beings, cost of damage calculated/ estimated in monetary terms, loss of animals mainly cattle, loss of vegetation, and loss of infrastructural facilities. In addition to these classification, some parameters of Hazard Risk Magnitude have been found out to determine magnitude and severity of natural hazards, such as Richter and Marcali scales to measure earthquakes; Fuijita scale to measure the severity and magnitude of tornados; Saffir-Simpson hurricane damage scale (5-point scale, minimum damage, moderate damage, extensive damage, extreme damage and catastrophic damage) etc. Hazard Risk Communication is another important factor of Disaster Reduction and Management. It is also called risk information having two components - a) risk communication system or transmission of hazard and disaster risk information to different segments of society, government and non-governmental organisations (NGO), and b) takers (receivers) of disasters risk information i.e. vulnerable and threatened sections of society [29].

\section{Approaches to Managing Disaster}

Though the extent of vulnerability of a population determines the scale of a natural hazard induced disaster, there are three major viewpoints to look at vulnerability. Firstly see vulnerability as natural event and subsequently put a technology bias while dealing with modes and means of their mitigation. The second view remains anchored on the premise that mankind itself has emerged as triggering agent of many such events by aggressively appropriating nature through the use of technology. The third view which appears as an extension of the second, emphasizes the variations in social formation of nations and the manner in which their human geography get organized on their socioeconomic space influences the scale of disasters and their impact. Various other approaches to mitigate and manage disasters seem to emerge from these three approaches of viewing disasters. In this respect, it is noteworthy that UN declaration of 1990-2000 as International Decade for Disaster Reduction was not only instrumental in bringing into sharp focus on devastations caused by natural disasters, but also introduced a paradigm shift from post disaster relief and reconstruction to adopting a pre-disaster pro-active approach. In May 1994, a mid-term review of UN declaration held at Yokohama concluded that i) such disasters always affected the poor and the socially disadvantaged in the developing countries most, owing to higher degree of their vulnerability to such situations; ii) prevention and mitigation of disasters are better than disaster response which are often executed at a very high cost and yield only some temporary relief; and iii) prevention contributes to lasting improvements in safety. These pointers are valid across the globe and for India they are very important [30]. Within the context of disaster vulnerability in India and in response to the 1994 Yokohama declaration, Government of India constituted an Expert Group (Building Material and Technology Promotion Council - BMTPC) [31] for studying certain specific issues relating to impact of natural hazards especially with respect to housing and infrastructure. Strong emphasis was put on :- i) the need to identify earthquakes, cyclones and flood related vulnerable areas prone to hazard of damaging houses and infrastructure, ii) formulating policies and legal institutional structures for enforcing disaster resistant construction in the hazard-prone settlements; and iii) preparing detailed natural vulnerability maps. The Expert Group (BMTPC) had emphasized on 


\section{International Journal of Science and Research (IJSR) \\ ISSN (Online): 2319-7064}

Index Copernicus Value (2015): 78.96 | Impact Factor (2015): 6.391

modifying and evolving a national policy on natural disaster and they highlighted following points in their report [32] a) Need for restructuring the existing policy so as to carefully include prevention, mitigation and preparedness in pre-disaster phase. b) Awareness creation for disaster reduction among cross section of professionals and institutions including policy makers, administrators, decision-makes, architects, engineers, NGOs, banks and other financial institutions, c) Increasing preparedness among communities living in vulnerable areas through use of media, school education and other appropriate method. d) Introduction of relevant amendments in the legislative and regulatory instruments (State laws, master plans, building regulations and bye laws of local bodies). e) Work towards capacity building at various levels for undertaking assessment surveys and investigations on the nature and extent of damage in post disaster situations. f) Ensuring disaster resistant construction in houses and building by law as well as incentives and disincentives. g) Working towards framing of policy instruments and generating funding support for disaster preparedness and prevention actions in high risk areas [33]. On similar ground a comprehensive Disaster Management Act 2005 [34] and India's $1^{\text {st }}$ National Disaster Management Plan, 2016 [35] is a significant development in India's Approach to Disaster Management.

\section{a) Pro-Active Disaster Management and Mitigation}

We seem to lack in having any sound database on people's experiences dealing with disasters and the manner in which they tend to cope with them. Any systematic approach of mitigation and preparedness essentially stem from such sets of knowledge, much of which need to be appropriately collate and subsequently integrated into any disaster mitigation approach or a related management exercise. The second important factor of disaster management and mitigation remains the need of increasing the awareness, sensitivity and preparedness to respond to such situations among the decision makers, administrators and especially those professionals who are dealing with the shaping of 'built environment'. This undoubtedly needs a review of the current practices of land-use and town planning; and a political will to implement necessary controls and regulations. The third important element of managing and mitigating disasters is to have detailed sets of data and information on phenomenon that lead to disasters. Scientifically collated and analyzed time series data on climatological, geological, hydrological and environmental aspects can enhance our understanding of natural events, their likely impact on life and property and development of effective warning systems [36].

\section{b) Rescue and Relief}

In response to large scale catastrophic events involving massive loss of life and property, it was observed that a section of such voluntary and quasi-voluntary aid has the will as well as the capacity to work, but many of them do not have needed skill to participate in the rescue operations. At such times it becomes the primary responsibility of the state machinery to - a) organize the rescue operations, b) channelize available human power into areas where they can be used more appropriately; c) effectively use the expertise of domestic as well as international agencies specializing in the rescue of life; and d) engage army and para-military forces. NDRF [Section 44 (1) of DMA, 2005 reads: "There shall be constituted a National Disaster Response Force for the purpose of specialist response to a threatening disaster situation or disaster."] and the army or specialized team can work towards organizing the much needed emergency water supply and demolishing damaged structures that threaten to fall. In situation of large scale devastation spread across large geography there is always need of more human power and equipment. But the supply of such equipment should be mobilized fast through their large-scale production on an emergency basis. Unless all the agencies involved in rescue operations are in coordination, the work put in will generate lesser efforts. Here, it becomes the responsibility of the state administration to regulate such flush of supplies through a robust delivery mechanism system [38]. In addition to regulating and organising distribution system governments need to evacuate people from the most vulnerable areas hit by disasters. In order to reduce such possibilities, households should be involved in the process of reconstruction from very beginning. Such, steps are possible especially in those rural pockets where large proportion of dwelling units were constructed out of locally available materials.

\section{c) Health and Medical Services}

In the aftermath of a disaster, maintenance of hygiene through quickly reorganized sanitation system and restoring supply of potable water becomes absolutely essential. Another challenge is to reduce potential out-break of disease and in case of occurrence of disease, how to check the spread of that disease to avoid spread of epidemic. Disasters never cause epidemics but the lack of timely actions and mis-management that led to such situations. Unplanned garbage disposable system can trigger the process of contamination of food and fodder. In disasters like earthquakes, timely disposal of dead bodies is one of the foremost tasks to be performed; provision of timely treatment to the injured comes under the top priority areas needing immediate attention. It is worth mentioning here that similar to initial flush of relief materials there is often an excess of common pills, medicines and number of medical personnel representing various public and private agencies. Their proper deployment is also an important function under disaster management and mitigation [39].

\section{d) Role of Administrative Coordinators}

Rescue and relief are the two most essential and immediate steps that need to be taken almost as a spontaneous response to any post disaster situation. In order to regulate various tasks related to rescue and relief in any disaster affected region within the country, the job of its total coordination should rest with the state administration. It should be aware about what is happening where and how on a continuous basis. The State administration managing the impact of a disaster should also be able to coordinate and regulate the works of various NGOs. Many such agencies coming with relief from farther areas hardly ever have a good knowledge of the geography as well as socio-economic environment of affected regions. Under such circumstances, channelizing such relief from specific centralized points to different zones as per feedback received from a continuously monitored need assessment system can yield better results. 


\section{International Journal of Science and Research (IJSR) \\ ISSN (Online): 2319-7064 \\ Index Copernicus Value (2015): 78.96 | Impact Factor (2015): 6.391}

e) Reconstruction and Rehabilitation

The work associated with rescue and relief in any disaster ends soon through some components of relief may overspill in the process of reconstruction and rehabilitation. Reconstruction generally involves two sets of processes, which are a) physical and b) economic - both of which need to be initiated simultaneously. Physical reconstruction essentially involves restoration or creation of social infrastructure including school, community halls, water supply, roads, communication links, shelters etc. Economic reconstruction which is largely a part of rehabilitation process largely aims at: a) restoring the earlier economic arrangements and networks of the affected population; b) linking people with the newer economic opportunities and markets thorough creation of appropriate institutional structures as provisions of grants, subsidies and credit; and c) increasing the negotiating capabilities of poor and marginalized sections across different communities through capacity building at the grassroots level [40].

\section{Conclusion}

For having a robust disaster management and reducing disaster impact, it is important to ex-ante risk reduction investment in development planning. Projects planned in disaster prone areas should mandatorily take disaster risk audit of the project. There has to be a more people-centric preventive approach to disaster management. Government should facilitate, engage with relevant stakeholders in design and implementation of policies, plans and standards aimed at disaster management.

\section{References}

[1] Rakesh Kanwar, "Disaster Management" (2001) XLIV The Administrator 96-110, at 98.

[2] Meera S., "Legal Regulation of Disaster Management in India: A Critical Analysis" (2010) 34 No. 1\&2 The Academy Law Review 135- 171, at 135.

[3] S.A.K. Azad, "Natural Hazards - Disaster Management \& Mitigation Strategies in India" (2013) Vol. XL (3) Indian Bar Review 45-51, at 46.

[4] Savindra Singh, Jeetendra Singh, Disaster Management (Allahabad : Pravalika Publications, 2013) at 12.

[5] Jaya V.S., "Disasters : A Challenge to Human Security" $16-39$, at 34 in: Vishnu Konoorayar, Jaya V.S. (eds.) Disaster Management and Law (New Delhi : Indian Law Institute, 2005).

[6] UNISDR Terminology on Disaster Risk Reduction (Geneva, Switzerland : UNISDR, 2009) at 17.

[7] Meera, Supra n. 2 at 139.

[8] UNISDR, Supra n.6 at 30.

[9] Meera, Supra n. 2 at 136.

[10] Stephane Hallegatte, Valentine Przyusky, The Economics of Natural Disaster : Concepts and Methods (The World Bank, Sustainable Development Network Office of the Chief Economist, 2010) Policy Research Working Paper 5507, at 2. Available at $\mathrm{http}: / /$ econ.worldbank.org. (Accessed on 21.01.17).

[11] Article 1 (6) of Tampere Convention on the Provision of Telecommunication Resources for Disaster Mitigation and Relief Operations, June 18, 1998.
United Nations Treaty Series, Vol. 2296, at 5. Available at http://www.ifrc.org/Docs/idrl//271EN.pdf (Accessed on 24.07.16).

[12] Article 1 (3) of ASEAN Agreement on Disaster Management and Emergency Response July 26, 2005 Available at

http://agreement.asean.org/media/download/

20140119170000.pdf (Accessed on 24.07.16). Referred in Vedhavathi, Id.

[13] Savindra, Supra n.4 at 4.

[14] Meera, Supra n. 2 at 139-140.

[15] Savindra, Supra n. 4 at 16.

[16] Disaster Management Notes and Questions. Available athttp://www.cyen.org/innovaeditor /assets/Disaster_Management_Notes_and_Questions.p df (Accessed on 21.01.17).

[17] D.K. Mishra, "Activity and Responses to Natural Disaster Management" (2010) 46 No.2 Civil and Military Law Journal 145-148, at 145-146.

[18] Meera, Supra n. 2 at 140-141.

[19] Disaster Prevention involves outright avoidance of adverse impact of hazards and related environmental and technological disasters. The culture of prevention should be inculcated in all communities which somehow reduce the impact of disasters. Early warning and conscious developmental program are key elements of preventive planning.

[20] Disaster Preparedness encompasses the measures taken before a disaster occurs. This aims at minimizing loss of life, disruption of critical services etc. The aim of disaster preparedness is to minimize adverse effect of hazard through effective precautionary actions. The United Nations Disaster Relief Office (UNDRO) defines disaster preparedness as a series of measures designed to organized and facilitate timely and effective rescue, relief and rehabilitation operations in case of disasters. The measures of preparedness include setting up of disaster relief machinery, formulation of emergency relief plan, training of specific groups (Vulnerable communities) to understand rescue and relief etc.

[21] Disaster Response is the sum total of action taken by people and institutions in the face of disasters. These actions commence with the warning of an oncoming threatening event or with the event itself if it occurs without warnings.

[22] Mitigation means lessening the impact of hazards. Mitigation refers to the efforts for reducing the actual or probable effects of a disaster on people, structures, economic and social system and the environment.

[23] Rehabilitation is the action taken in the aftermath of a disaster to enable basic services to resume functioning, assist, victims, self-help efforts to repair dwellings and community facilities and facilitate the revival of economic activities. Rehabilitation means setting the people back to their normal lives as far as possible through well laid out plans.

[24] Reconstruction means the action taken to reestablish a community after a period subsequent to disaster this would include construction of permanent houses, full restoration of all services and complete resumption of pre-disaster state. 


\section{International Journal of Science and Research (IJSR) \\ ISSN (Online): 2319-7064}

Index Copernicus Value (2015): 78.96 | Impact Factor (2015): 6.391

[25] Government of India, National Policy on Disaster Management, 2009 (New Delhi : NDMA, 2009 ) at 7.

[26] Rakesh, Supra n. 1, at 105-109.

[27] The Federal Emergency Management Agency (FEMA) is an agency of the United States Department of Homeland Security. The agency's primary purpose is to coordinate the response to a disaster that has occurred in the United States. Available at: https://www.fema.gov/about-agency. (Accessed on 25.1.2017)

[28] Savindra, Supra n. 4 at 17,19.

[29] Ibidem.

[30] Biswaroop Das, "Some Aspects of Disaster Mitigation and Management in India" (2002) Vol. XLVIII No.2, Indian Journal of Public Administration 183 - 196, at 185.

[31] Building Material and Technology Promotion Council (BMTPC), "Disaster Mitigation and Vulnerability Atlas of India - A Paradigm Shift from Post- Disaster Reconstruction and Relief to Pre-Disaster Pro-Active Approach" (New Delhi: Ministry of Urban Development and Poverty Alleviation, 2001).

[32] Ibidem

[33] Das, Supra n. 30 at 187.

[34] Disaster Management Act 2005 was passed 23.12.2005.

[35] The $1^{\text {st }}$ National Plan on Disaster Management was released by PM Narendra Modi on May 2016 in New Delhi. Available

http://ndma.gov.in/images/policyplan/dmplan/National $\% 20$ Disaster\%20Management $\% \quad 20$ Plan\% 20May\%202016.pdf. Assessed on 28.12.16

[36] Das, Supra n. 30 at 189.

[37] Ibidem.

[38] Id.

[39] Das, Supra n. 30 at 194. 